\begin{tabular}{|ccl}
\hline 45 & Jurnal Teknologi Kimia Unimal & $\begin{array}{l}\text { Jurnal } \\
\text { Teknologi } \\
\text { Kimia } \\
\text { Unimal }\end{array}$ \\
\hline
\end{tabular}

\title{
Optimasi Proses Pembuatan Biodiesel Biji Jarak Pagar (Jatropha Curcas L.) Melalui Proses Ekstraksi Reaktif
}

\author{
Retno Atika Putri ${ }^{1}$, Azhari Muhammad ${ }^{1}$ Ishak $^{1}$ \\ ${ }^{1}$ Jurusan Teknik Kimia, Fakultas Teknik, Universitas Malikussaleh \\ Laboratorium Teknik Kimia, Jl. Batam No. 2, Lhokseumawe 24353, Indonesia \\ e-mail: retnoatikaputri@gmail.com
}

\begin{abstract}
Abstrak
Biodiesel merupakan suatu bahan bakar alternatif yang ramah lingkungan.Dalam penelitian ini bahan dasar yang digunakan dalam pembuatan biodiesel biji jarak pagar. Proses pembuatan biodiesel yang digunakan adalah ekstraksi reaktif, yaitu proses ekstraksi dan reaksi transesterifikasi, berjalan secara simultan, dimana metanol memliki fungsi ganda, yaitu sebagai pelarut dan sebagai reaktan. Pelarut yang digunakan pada penelitian ini adalah nheksana. Adapun tujuan dari penelitian ini adalah untuk mencari kondisi optimum proses pembuatan biodiesel dari Jatropha curcas L. seed (biji jarak pagar) dengan menggunakan Software Design Expert V.6.0.8 metode Response Surface Methodology (RSM) Box Behnken Design (BBD). Biji jarak pagar sebanyak $200 \mathrm{gr}$, menggunakan pelarut $\mathrm{CH} 3 \mathrm{OH}$ dan katalis $\mathrm{KOH}$ sebesar $0,8 \% \mathrm{w} / \mathrm{w}$ dengan perbandingan mol (minyak:alkohol) adalah 1:4, 1:5, 1:6, suhu reaksi 55, 60 dan $65^{\circ} \mathrm{C}$ dengan waktu reaksi adalah 60 menit, 120 menit dan 180 menit. Berdasarkan hasil eksperimen diperoleh yield tertinggi sebesar $12,80 \%$ pada kondisi 120 menit pada suhu $60^{\circ} \mathrm{C}$ dan perbandingan mol 1:5, sedangkan Design Expert memberikan prediksi untuk memperoleh titik optimal yaitu, pada kondisi suhu $60^{\circ} \mathrm{C}$ perbandingan mol 1:5,03 dan lama reaksi berlangsung adalah selama 131,92 menit dengan yield biodiesel sebesar 12,88\%.Biodiesel merupakan suatu bahan bakar alternatif yang ramah lingkungan. Dalam penelitian ini bahan dasar yang digunakan dalam pembuatan biodiesel biji jarak pagar. Proses pembuatan biodiesel yang digunakan adalah ekstraksi reaktif, yaitu proses ekstraksi dan reaksi transesterifikasi, berjalan secara simultan, dimana metanol memliki fungsi ganda, yaitu sebagai pelarut dan sebagai reaktan. Pelarut yang digunakan pada penelitian ini adalah nheksana. Adapun tujuan dari penelitian ini adalah untuk mencari kondisi optimum proses pembuatan biodiesel dari Jatropha curcas L. seed (biji jarak pagar) dengan menggunakan Software Design Expert V.6.0.8 metode Response Surface Methodology (RSM) Box Behnken Design (BBD). Biji jarak pagar sebanyak 200 gr, menggunakan pelarut $\mathrm{CH} 3 \mathrm{OH}$ dan katalis $\mathrm{KOH}$ sebesar $0,8 \% \mathrm{w} / \mathrm{w}$ dengan perbandingan mol (minyak:alkohol) adalah 1:4, 1:5, 1:6, suhu reaksi 55, 60 dan $65^{\circ} \mathrm{C}$ dengan waktu reaksi adalah 60 menit, 120 menit dan 180 menit. Berdasarkan hasil eksperimen diperoleh yield tertinggi sebesar 12,80\% pada kondisi 120 menit pada suhu $60^{\circ} \mathrm{C}$ dan perbandingan mol 1:5, sedangkan Design Expert memberikan prediksi untuk memperoleh titik optimal yaitu, pada kondisi suhu $60^{\circ} \mathrm{C}$ perbandingan mol 1:5,03 dan lama reaksi berlangsung adalah selama
\end{abstract}


131,92 menit dengan yield biodiesel sebesar 12,88\%.

Kata kunci $\quad$ : Biodiesel, ekstraksi reaktif, minyak jarak pagar, Response

Surface Methodology, transesterifikasi

\section{Pendahuluan}

Saat ini, bahan bakar fosil merupakan sumber energi secara global. Namun, persediaan energi fosil seperti minyak, gas dan batubara di Indonesia yang selama ini digunakan semakin menipis, dan akan diperkirakan habis pada tahun 2025. Indonesia sedang mengalami krisis energi dan terpaksa harus impor BBM dari negara asing, padahal Indonesia merupakan salah satu negara penghasil minyak bumi di dunia. Oleh karena itu, untuk mengatasi permasalahan ini diperlukan usaha-usaha untuk mencari bahan energi terbarukan (renewable energy). Salah satu bahan bakar alternatif yang ramah lingkungan dan berasal dari sumber daya yang dapat diperbaharui adalah biodiesel.

Menurut American Society for Testing Materials (ASTM Internasional), biodiesel didefinisikan sebagai mono-alkil ester rantai panjang asam lemak yang berasal dari sumber yang terbarukan, yang digunakan untuk mesin diesel. Biodiesel merupakan bahan bakar terbarukan, biodegradable, tidak beracun, dan ramah lingkungan. Biodiesel menghasilkan emisi yang lebih rendah, memiliki titik flash tinggi, daya pelumas yang lebih baik, dan cetane number tinggi. Penggunaan biodiesel memiliki potensi untuk mengurangi tingkat polusi dan kemungkinan karsinogen [Novalina, 2015].

Tanaman jarak pagar (Jatropha curcas L.) merupakan salah satu tanaman yang berpotensi sebagai bahan bakar alami terbarukan. Tanaman ini sangat cepat tumbuh dan struktur akarnya mampu menahan erosi, terutama apabila ditanam dengan jarak yang sangat rapat. Biji jarak merupakan bagian dari tanaman jarak pagar yang mengandung minyak cukup tinggi. Tanaman sejak lama dikenal sebagai tanaman konservasi karena sifatnya yang sangat toleran terhadap jenis tanah dan iklim.

Metode konvensional untuk memproduksi biodiesel dari minyak jarak dan tipe lainnya terdiri dari beberapa tahap, yaitu ekstraksi minyak, purifikasi dan reaksi esterifikasi atau transesterifikasi, proses ini merupakan proses yang panjang. Metode pengolahan ini menghabiskan $70 \%$ dari total biaya produksi jika 
refined oil digunakan sebagai bahan baku. Pengembangan ekstraksi reaktif memiliki potensi untuk mengurangi biaya pengolahan dengan segala jenis bahan baku. Hybrid atau proses simultan yang meng-kombinasikan reaksi dan proses pemisahan adalah satu hal yang telah menerima banyak perhatian akhir-akhir ini dikarenakan untuk menghemat biaya investasi dan energi dan beberapa hal lain. Ekstraksi reaktif adalah proses yang melibatkan reaksi dan pemisahan dilakukan secara bersamaan. Pemisahan fase dapat dilakukan secara alami dalam sistem reaktif dengan menambahkan pelarut. Alkohol bertindak sebagai pelarut di proses ekstraksi dan sebagai reagent pada reaksi transesterifikasi selama ekstraksi reaktif berlangsung [Supardan, 2013]. Berdasarkan pemikiran yang telah dipaparkan, maka penulis melakukan penelitian pembuatan biodiesel minyak jarak pagar (Jatropha curcas L.) dengan menggunakan ekstraksi reaktif, sehingga metode ini nantinya dapat dikembangkan untuk skala industri dan mampu meminimalkan dampak lingkungan.

\section{Tinjauan Pustaka}

Tanaman jarak dapat tumbuh di tanah yang kering, mudah tumbuh dengan cepat dan tanaman ini dapat menghasilkan biji selama 40 tahun. Tanaman jarak ini mnghasilkan biji dengan kandungan minyak hingga 37\%, hampir dua kalilipat dibandingkan kedelai dan hampir sama dengan kandungan minyak pada camelina. Minyak dari tanaman ini dapat diekstrak dari bijinya setelah 2 hingga 5 tahun penanaman, tergantung kualitas tanah dan curah hujan [Honary, L.A.T, 2011].

Bunga tanaman jarak berwarna kuning kehijauan, berupa bunga majemuk berbentuk malai, bermah satu. Buah berupa buah kotak berbentuk bulat telur, diameter 2-4 cm, berwarna hijau ketika masih muda dan kuning ketika telah masak. Buah jarak terbagi 3 ruang yang masing-masing ruang diisi 3 biji. Biji berbentuk bulat lonjong, warna coklat kehitaman. Biji inilah yang banyak mengandung minyak dengan rendemen sekitar 30-40\%. Minyak jarak pagar diperoleh dari biji dengan metode pengempaan panas atau dengan ekstraksi pelarut. Minyak jarak pagar tidak dapat dikonsumsi manusia karena mengandung racun yang disebabkan adanya senyawa ester forbol [Syah, 2006]. 
Biodiesel digunakan sebagai bahan bakar alternatif pengganti, sangat baik bagi lingkungan, diproduksi dalam negeri dengan sumber daya alam untuk mengurangi ketergantungan terhadap bahan bakar impor dan dapat memberikan kontribusi untuk perekonomian negara [biodiesel.org, 2016]. Menurut American Society of Testing Material bahwa biodiesel adalah bahan bakar alternatif yang menjanjikan yang dapat diperoleh dari minyak tumbuhan, lemak binatang atau minyak bekas melalui esterifikasi dengan alkohol. Sumber alkohol yang digunakan dapat bermacam-macam. Apabila direkasikan dengan metanol, maka akan didapati metil ester, apabila direaksikan dengan etanol akan diperoleh etil ester. Metanol lebih banyak digunakan sebagai sumber alkohol karena rantainya lebih pendek, lebih polar dan harganya lebih murah dari alkohol lainnya (Ma dkk., 2001).

\subsection{Pembuatan Biodiesel}

Pembuatan biodiesel dapat dilakukan dengan cara 2 langkah, yaitu esterifikasi dan transesterifikasi. Proses esterifikasi bertujuan untuk menurunkan kadar FFA minyak/lemak yang akan digunakan. Bahan baku minyak jarak dan minyak jelantah harus mengandung asam lemak bebas dalam minyak serendah mungkin $(<1 \%)$. Adanya sedikit kandungan asam lemak bebas dalam reaktan akan menyebabkan terbentuknya sabun dan akan menurunkan yield ester serta mempersulit pemisahan pemisahan ester dan gliserol. Kehadiran asam lemak bebas dalam minyak juga akan mengkonsumsi katalis sehingga menurunkan efisiensi katalis. Transesterifikasi berkatalis basa akan efisien jika bahan baku minyak berkemurnian tinggi (Rahmania, 2004).

Reaksi transesterifikasi disebut juga dengan reaksi alkoholisis. Alkohol yang biasa digunakan dalam rekasi tranesterifikasi adalah metanol. Proses transestrifikasi dengan menggunakan katalis basa mampu mencapai $98 \%$ konversi dengan waktu reaksi minimum. Berikut ini adalah reaksi pembentukan metil ester dapat dilihat pada Gambar 1, sedangkan tahap-tahap reaksi transesterifikasi yang ditampilkan dalam Gambar 2. 
Reaksi terjadi secara bertahap. Pada reaksi pertama adalah konversi dari trigliserida menjadi digliserida, diikuti dengan digliserida menjadi monogliserida, dan terakhir adalah monogliserida menjadi gliserol, menghasilkan satu molekul metil ester dari setiap gliserida pada setiap tahap. Reaksi transesterifikasi dilakukan menggunakan katalis basa kuat, yaitu $\mathrm{KOH}$. Menurut Encinar dkk. (1999), melaporkan bahwa dibandingkan dengan $\mathrm{NaOH}$, kinerja $\mathrm{KOH}$ sebagai katalis lebih unggul dimana produk metil ester yang dihasilkan lebih banyak serta pemisahan produk metil ester dari gliserol lebih mudah. Kombinasi antara katalis $\mathrm{KOH}$ dengan pelarut metanol dalam reaksi transesterifikasi diharapkan dapat menghasilkan produk biodiesel yang maksimal.

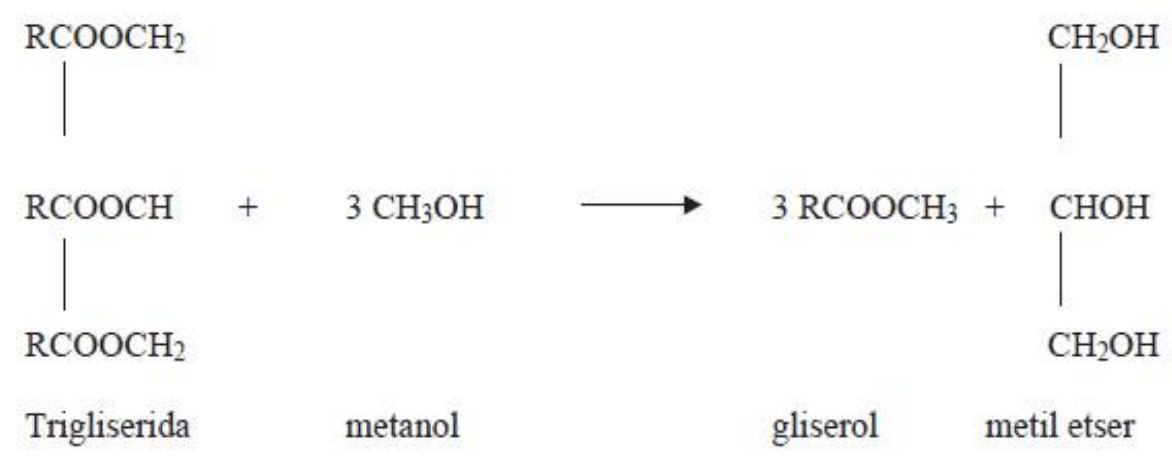

Gambar 1 Reaksi Pembentukan Metil Ester

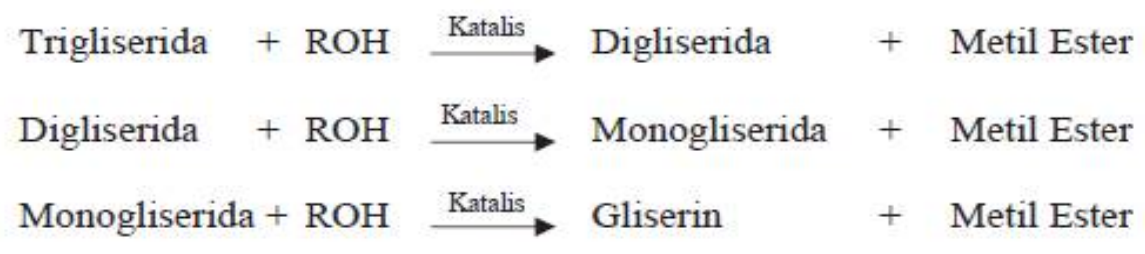

Gambar 2 Tahapan-tahapan Reaksi Transesterifikasi (Syam, 2012)

Tujuan reaksi transesterifikasi adalah untuk menghilangkan secara utuh kandungan trigliserida, titik didih, titik nyala, viskositas dari minyak yang direaksikan, agar metil ester yang dihasilkan dapat digunakan pada mesin diesel tanpa merusak atau merubah mesin diesel.

\subsection{Ekstrasksi}

Ekstraksi adalah proses pemisahan suatu zat berdasarkan perbedaan kelarutan terhadap dua cairan yang tidak saling larut. Prinsip ekstraksi adalah 
melarutkan minyak atsiri dalam bahan dengan pelarut organik yang mudah menguap. Metode konvensional untuk memproduksi biodiesel dari minyak jarak dan tipe lainnya terdiri dari beberapa tahap, yaitu ekstraksi minyak, purifikasi dan reaksi esterifikasi atau transesterifikasi. Ini merupakan proses yang panjang Metode pengolahan ini menghabiskan $70 \%$ dari total biaya produksi jika refined oil digunakan sebagai bahan baku. Pengembangan ekstraksi reaktif memiliki potensi untuk menrurangi biaya pengolahan sengan segala jenis bahan baku. Hybrid atau proses simultan yang meng-kombinasikan reaksi dan proses pemisahan adalah satu hal yang telah menerima banyak perhatian akhir-akhir ini dikarenakan untuk menghemat biaya investasi dan energi dan beberapa hal lain.

Ekstraksi reaktif adalah proses yang melibatkan reaksi dan pemisahan dilakukan secara bersamaan. Pemisahan fase dapat dilakukan secara alami dalam sestem reaktif dengan menambahkan pelarut. Alkohol bertindak sebagai pelarut di proses ekstraksi dan sebagai reagent di reaksi transesterifikasi selama ekstraksi reaktif berlangsung. Oleh sebab itu alkohol diperlukan dalam jumlah yang sangat banyak (Supardan, 2013).

\section{Metode Penelitian}

Adapun tahapan dalam melakukan penelitian ini meliputi persiapan bahan baku, tahapan penelitian, dan tahap analisa. Biji buah jarak yang sudah tua dibersihkan terlebih dahulu. Setelah itu dihancurkan, kemudian dikeringkan hingga suhu $76{ }^{\circ} \mathrm{C}$. Biji yang telah dihaluskan dan dikeringkan, ditimbang sebanyak 200 gram dan dimasukkan ke dalam lab leher tiga (reaktor). Selanjutnya $600 \mathrm{ml}$ pelarut n-heksana dan $\mathrm{KOH}$ yang telah dilarutkan dengan metanol dimasukkan ke reaktor. Perbandingan mol 1:4 (minyak:metanol), metanol sebanyak $40 \mathrm{ml}$ dimasukkan ke dalam reaktor. Campuran dipanaskan pada suhu $55^{\circ} \mathrm{C}$. Campuran di-homogenkan dengan kecepatan pengadukan $400 \mathrm{rpm}$ selama 1 jam.

Setelah ekstraksi reaktif selesai, peralatan pemanas dimatikan dan campuran reaksi dikeluarkan dari reaktor. Campuran dipisahkan dengan proses penyaringan menggunakan kertas saring, sedangkan residu yang tersisa dibuang. 
Filtrat yang diperoleh di-destilasi hingga suhu $70{ }^{\circ} \mathrm{C}$ untuk menghilangkan pelarut (n-heksana dan metanol) dari minyak. Minyak yang telah dipisahkan dari pelarut dimasukkan ke dalam corong pemisah selama beberapa jam sehingga terlihat 2 lapisan, yaitu lapisan atas adalah metil ester dan lapisan bawah adalah gliserol. Metil ester atau biodiesel yang telah diperoleh, dicuci dengan air hangat (suhu $50{ }^{\circ} \mathrm{C}$ ) untuk menghilangkan residu katalis dan sabun. Gliserol merupakan produk samping dari proses ini, maka gliserol dipisahkan dari biodiesel. Selanjutnya, biodiesel dikeringkan untuk mengurangi kadar air, kemudian dilakukan analisa hasil. Untuk variabel lain akan dilakukan dengan langkahlangkah yang sama tetapi dengan mengubah variabel suhu, waktu reaksi dan perbandingan mol sesuai dengan yang diinginkan. Biodiesel yang diperoleh diambil untuk dianalisa yield, viskositas, densitas, moisture content, cloud point (F) dan pour point (F) dan analisa komposisi kimia biodiesel.

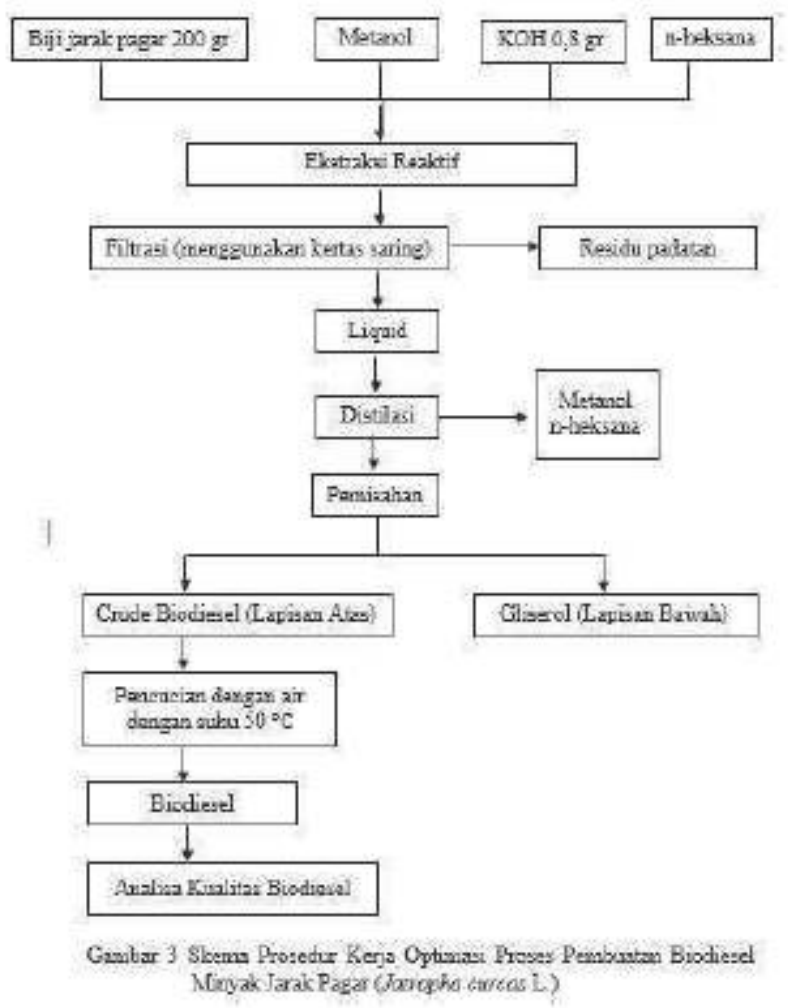

Metode yang digunakan untuk merancang percobaan ini adalah RSM (Metode Response Surface Methodology). RSM merupakan penggabungan teknik matematika dan statistik yang berguna untuk permodelan dan analisis problem 
yang mana respon yang diamati dipengaruhi oleh beberapa variabel dan bertujuan untuk mengoptimalkan hasil penelitian ini.

Adapun diagram optimasi proses pembuatan biodiesel minyak jarak pagar (Jatropha curcas L.) dengan menggunakan ekstraksi reaktif dapat dilihat pada Gambar 3.

\section{Hasil dan Pembahasan}

Penelitian ini didesain dengan menggunakan Response Surface Methodology (RSM) dengan software Design Expert V.6.0.8 Hasil penelitian berupa yield biodiesel diperoleh dari hasil perhitungan data penelitian yang dilakukan di Laboratorium Teknik Kimia Universitas Malikussaleh dan Laboratorium Politeknik Negeri Lhokseumawe.

Berdasarkan hasil penelitian yang diperoleh, maka data pengamatan proses pembuatan biodiesel biji jarak pagar (Jatropha curcas L.) melalui proses ekstraksi reaktif dapat dilihat pada Tabel 1.

Tabel 1 Data hasil Penelitian Menggunakan Box Behnken Method

\begin{tabular}{|c|c|c|c|c|}
\hline \multirow{2}{*}{ Run } & \multicolumn{3}{|r|}{ Variabel Bebas } & \multirow{2}{*}{$\begin{array}{c}\text { Variabel Terikat } \\
\text { Yield } \\
\%\end{array}$} \\
\hline & $\begin{array}{l}\text { Suhu } \\
{ }^{C} \mathrm{C}\end{array}$ & $\begin{array}{l}\text { Waktu } \\
\text { Menit }\end{array}$ & $\begin{array}{c}\text { Perbandingan mol minyak: metanol } \\
\text { Mol }\end{array}$ & \\
\hline 1 & 55,00 & 60,00 & 5,00 & 7,715 \\
\hline 2 & 65,00 & 60,00 & 5,00 & 7,467 \\
\hline 3 & 55,00 & 180,00 & 5,00 & 7,834 \\
\hline 4 & 65,00 & 180,00 & 5,00 & 10,586 \\
\hline 5 & 55,00 & 120,00 & 4,00 & 8,127 \\
\hline 6 & 65,00 & 120,00 & 4,00 & 7,576 \\
\hline 7 & 55,00 & 120,00 & 6,00 & 6,119 \\
\hline 8 & 65,00 & 120,00 & 6,00 & 5,892 \\
\hline 9 & 60,00 & 60,00 & 4,00 & 5,145 \\
\hline 10 & 60,00 & 180,00 & 4,00 & 3,885 \\
\hline 11 & 60,00 & 60,00 & 6,00 & 3,683 \\
\hline 12 & 60,00 & 180,00 & 6,00 & 8,800 \\
\hline 13 & 60,00 & 120,00 & 5,00 & 12,800 \\
\hline 14 & 60,00 & 120,00 & 5,00 & 12,800 \\
\hline 15 & 60.00 & 120,00 & 5,00 & 12,800 \\
\hline 16 & 60,00 & 120,00 & 5,00 & 12,800 \\
\hline 17 & 60,00 & 120,00 & 5,00 & 12,800 \\
\hline
\end{tabular}

Makalah sudah dipresentasikan dalam Seminar Nasional Teknik Kimia UNIMAL 2016 (17 Oktober 2016) 
Model kuadratik dipilih sebagai model permukaan respon aktivitas terhadap mol rasio, suhu dan waktu berdasarkan hasil pengujian yang telah dilakukan. Keakuratan model tersebut dapat diketahui dari harga R-squared yaitu R2 = 0,9537. Berdasarkan nilai tersebut dapat diambil kesimpulan bahwa nilai yield biodiesel yang diperkirakan dengan model mendekati nilai yang diperoleh dari hasil penelitian. Nilai R2 > 0,85 artinya model dapat diterima. Adapun model yang dihasilkan adalah bentuk persamaan matematis yang disusun sebagai berikut:

$$
\begin{aligned}
Y_{1}= & -280,541+6,500 A-0,067 \mathrm{~B}+40,278 \mathrm{C}-0,0570 \mathrm{~A}^{2}-0,001 \mathrm{~B}^{2}- \\
& 4,446 \mathrm{C}^{2}+0,0025 \mathrm{AB}+0,016 \mathrm{AC}+0,026 \mathrm{BC}
\end{aligned}
$$

Dimana: $\quad \mathrm{A}=$ suhu

$$
\begin{aligned}
& B=\text { waktu } \\
& C=\text { perbandingan } \mathrm{mol}
\end{aligned}
$$

\subsection{Interaksi antara suhu dan waktu}

Grafik tiga dimensi yang menunjukkan interaksi antara suhu dan waktu dapat dilihat pada Gambar 4.

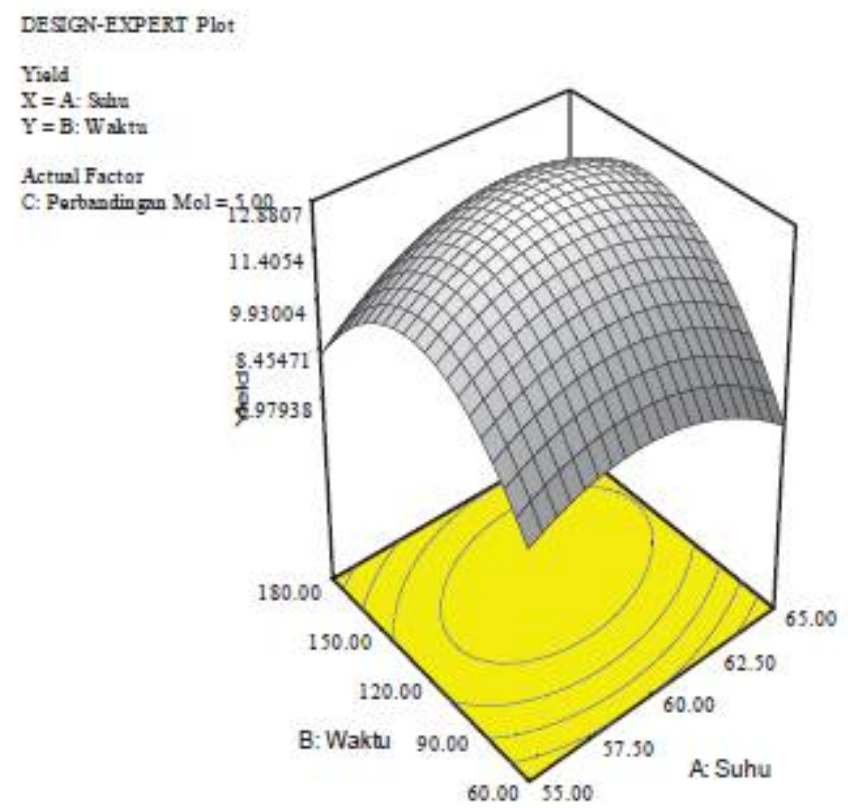

Gambar 4 Interaksi Antara Suhu dan Waktu

Gambar 4 menunjukkan interaksi antara suhu dan waktu. Pada umumnya 
reaksi transesterifikasi dilakukan pada suhu $60.65{ }^{\circ} \mathrm{C}$ pada tekanan atmosfer. Kecepatan reaksi akan meningkat sejalan dengan kenaikan temperatur, yang berarti semakin banyak energi yang dapat digunakan reaksi untuk mencapai energi aktivasi, sehingga akan menyebabkan semakin banyak tumbukan terjadi antara molekul-molekul reaktan.

Semakin lama waktu reaksi, maka semakin banyak ester yang dihasilkan. Hal ini dapat terjadi karena situasi ini akan memberikan kesempatan molekulmolekul reaktan untuk semakin lama bertumbukan. Grafik hubungan suhu dan waktu disajikan pada Gambar 5.

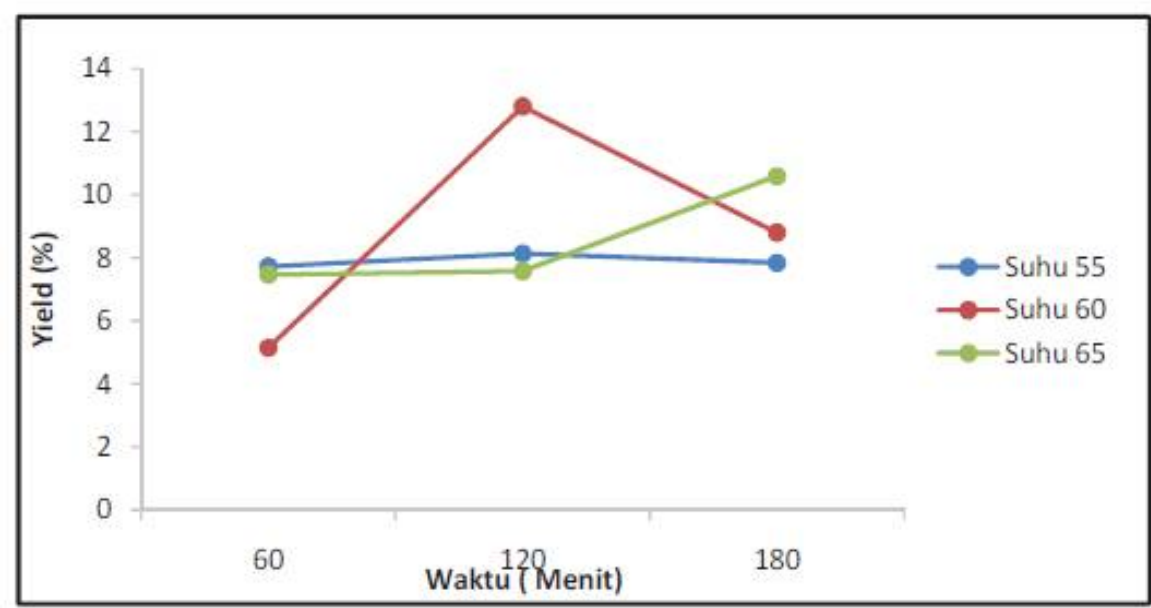

Gambar 5 Grafik Hubungan Suhu dan Waktu Reaksi terhadap Yield

Suhu reaksi yang digunakan pada proses transesterifikasi sebaiknya tepat, karena suhu yang berlebihan dapat menyebabkan reaksi menjadi tidak sempurna. Pada penelitian ini digunakan suhu bervariasi, yaitu 55,60 dan $65^{\circ} \mathrm{C}$. Gambar 5 di atas, menunjukkan bahwa semakin tinggi suhu reaksi yang dioperasikan, maka yield metil ester semakin besar. Hal ini terjadi karena dengan naiknya suhu reaksi, maka tumbukan partikel akan semakin besar, sehingga reaksi berjalan semakin cepat dan konstanta reaksi akan semakin besar. Ketika reaksi berlangsung selama 180 menit, pada suhu 55 dan $60{ }^{\circ} \mathrm{C}$ mengalami penurunan, karena pelarut (nheksana) dan metanol kemungkinan mengalami penguapan ketika reaksi berlangsung. Pada Reaksi ini merupakan reaksi endotermis, sehingga apabila suhu dinaikkan, maka kesetimbangan akan bergeser ke produk (Dogra, 1990). 


\subsection{Interaksi antara suhu dan perbandingan mol}

Berikut adalah grafik tiga dimensi yang menunjukkan interaksi antara perbandingan mol dengan suhu. Gambar di atas menunjukkan interaksi antara perbandingan mol dan suhu. Pada reaksi transesetrifikasi, penggunaan suhu yang tidak tepat dapat mengakibatkan reaksi tidak sempurna dan menyebabkan berkurangnya yield biodiesel. Penggunaan suhu yang tepat mengakibatkan reaksi bergeser ke arah kanan (produk), peningkatan laju reaksi ini disebabkan oleh meningkatnya konstanta laju reaksi yang merupakan fungsi dari temperatur. Reaksi transesterifikasi merupakan reaksi reversible, maka pada kondisi suhu yang tinggi kesetimbangan bergeser ke arah kiri (dekomposisi produk). Perbandingan reaktan yang semakin tinggi, maka semakin besar pula yield yang diperoleh. Hal ini dapat terjadi karena perbandingan mol reaktan yang berlebih, yang diharapkan reaksi akan bergeser ke kanan. Perbandingan mol 1:6 mengalami penurunan. Hal ini mungkin disebabkan oleh trigliserida yang telah habis bereaksi. Metanol yang digunakan adalah methanol teknis, dimana metanol tersebut masih mengandung air. Keberadaan air akan menyebabkan reaksi bergeser kea rah kiri. Reaksi transesterifikasi merupakan reaksi reversible yang menghasilkan produk samping berupa air.

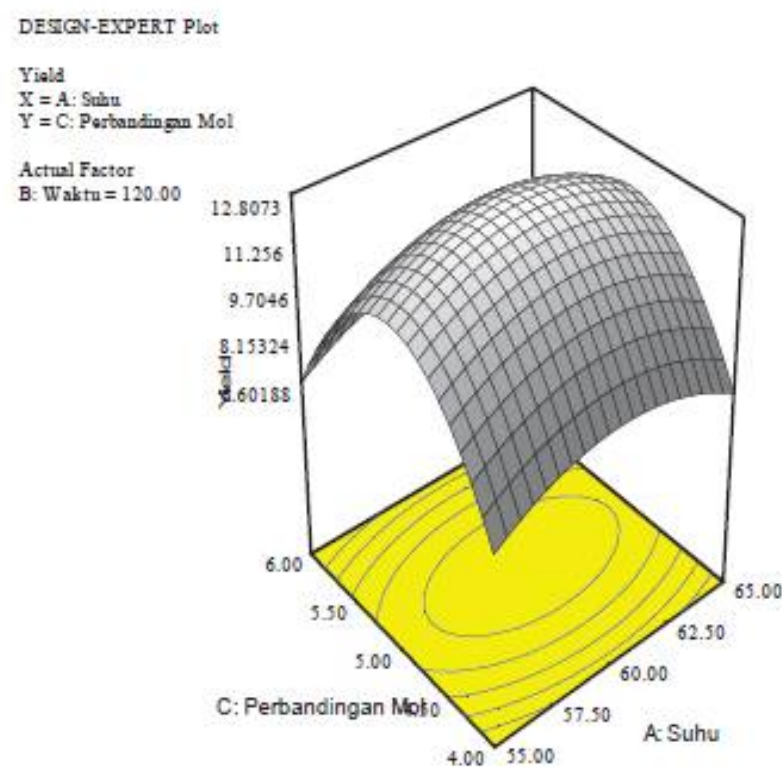

Gambar 6 Interaksi Antara Perbandingan Mol dan Suhu 


\subsection{Interaksi antara waktu dan perbandingan mol}

Grafik tiga dimensi yang menunjukkan interaksi antara waktu dan perbandingan mol dapat dilihat pada Gambar 8 dan grafik perbandingan mol terhadap waktu reaksi disajikan pada Gambar 9.

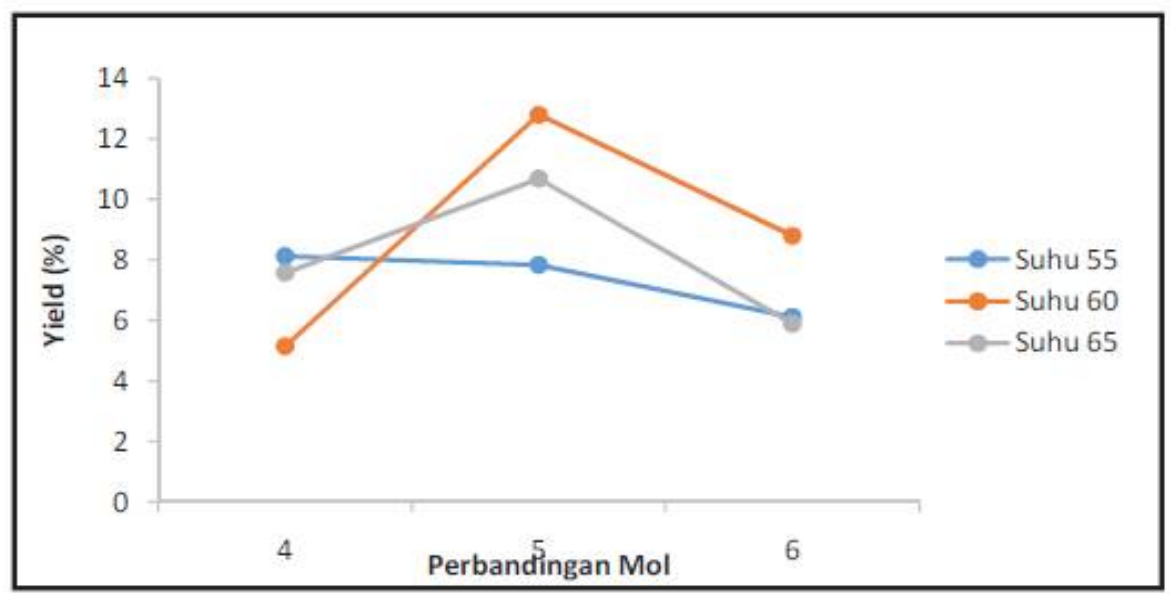

Gambar 7 Grafik Interaksi Antara Perbandingan Mol terhadap Yield

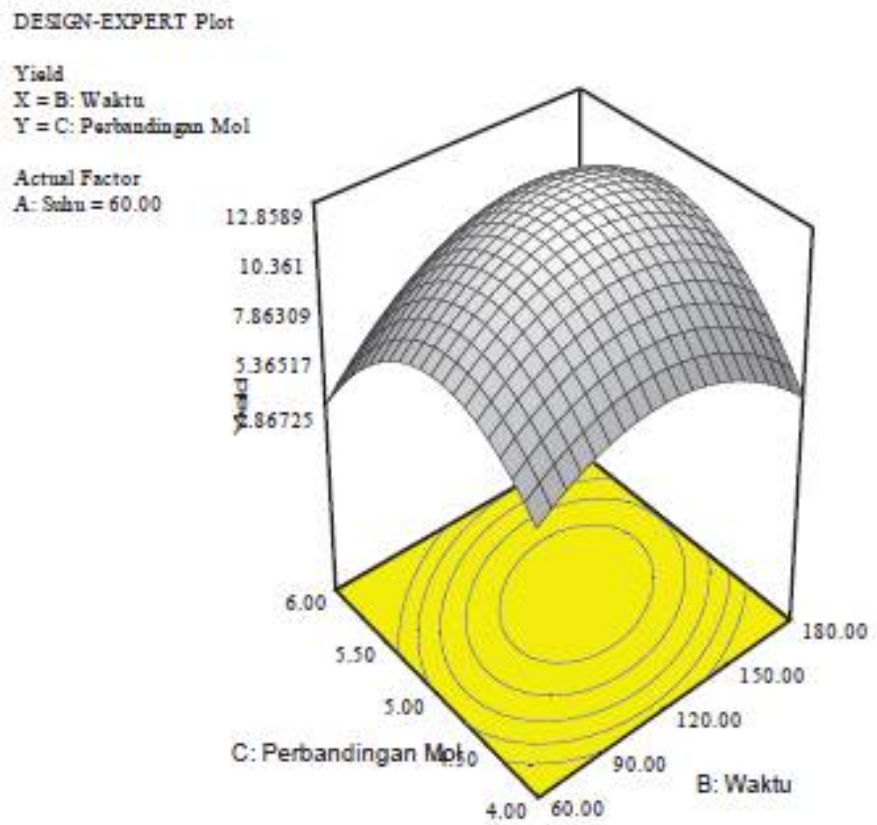

\section{Gambar 8 Interaksi Antara Waktu dan Perbandingan Mol}

Jumlah mol reaktan dalam pembuatan biodiesel juga mempengaruhi yield 
biodiesel. Secara umum ditunjukkan bahwa semakin banyak alkohol yang digunakan maka semakin banyak yield yang dihasilkan. Hal ini dikarenakan pemakaian reaktan yang berlebih akan memperbesar kemungkinan tumbukan antara zat molekul yang bereaksi sehingga kecepatan reaksinya bertambah besar. Penggunaan mol reaktan secara berlebihan juga dapat menyebabkan yield kecil. Kondisi ini dapat terjadi karena dengan penggunaan mol reaktan secara berlebihan, katalis tidak berperan secara signifikan dalam memperkecil energi aktivasi. Oleh karena itu, dengan waktu yang diberikan terbatas, kesempatan molekul untuk bertumbukan semakin kecil, inilah yang menyebabkan yield yang diperoleh kecil.

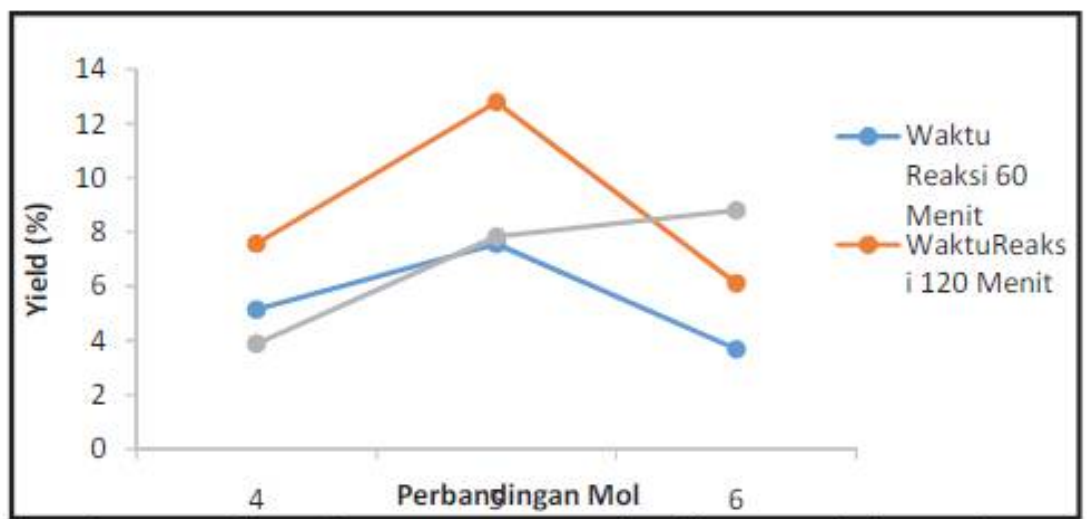

Gambar 9 Grafik Hubungan Antara Perbandingan Mol dan Waktu Reaksi terhadap Yield

\subsection{Analisa karakteristik biodiesel}

Hasil analisa yang diperoleh dari uji kualitas biodiesel ditampilkan pada Tabel 2.

Tabel 2 Hasil Analisa Karakteristik Biodiesel

\begin{tabular}{|c|c|c|c|}
\hline Karakteristik & Satuan & Biodiesel & SNI Biodiesel \\
\hline Massa jenis & $\mathrm{Kg} / \mathrm{m}^{3}$ & 867,6 & $850-890$ \\
\hline Viskositas pada $40^{\circ} \mathrm{C}$ & $\mathrm{cst}$ & 3,529 & $2,3-6,0$ \\
\hline Angka Asam Total & $\mathrm{MgKOH} / \mathrm{kg}$ & 2,644 & 0,6 maks \\
\hline Cloud Point & $\left({ }^{\circ} \mathrm{C}\right)$ & $-6{ }^{\circ} \mathrm{C}$ & $18{ }^{\circ} \mathrm{C}$ maks \\
\hline
\end{tabular}


Berdasarkan hasil yang diperoleh seperti tertera pada Tabel 2 dapat diketahui bahwa densitas, viskositas dan cloud point dari biodiesel yang diperoleh melalui penelitian ini sudah memenuhi karakteristik sebagaimana yang dikeluarkan oleh Standar Nasional Indonesia (SNI). Angka asam yang diperoleh melebihi standar SNI biodiesel, yaitu 0,6 maks. Angka asam yang tinggi dapat menyebabkan endapan dalam sistem bahan bakar dan juga merupakan indikator penurunan kualitas bahan bakar. Semakin tinggi angka asam terhadap biodiesel, maka semakin rendah pula kualitasnya. Angka asam yang tinggi dapat menyebabkan korosi dan memperpendek umur pompa maupun filter.

Selanjutnya minyak di analisa dengan menggunaka alat Gas Chromatography (GC) untuk mengetahui komposisi minyak. Gas Chromatography yang digunakan adalah GC Shimadzu Seri GC-2010 menggunakan kolom BD 5 AT dengan panjang diameter kolom 15 meter dan internal diameternya adalah $0,250 \mathrm{~mm}$. Suhu Injector kolom adalah $360^{\circ} \mathrm{C}$. Suhu kolom awal adalah $60^{\circ} \mathrm{C}$ kemudian ditahan selama 5 menit, dilanjutkan kembali dengan menaikkan selama 15 menit hingga suhu $350^{\circ} \mathrm{C}$, ditahan kembali selama 5 menit. Carier gas pada GC ini adalah nitrogen dengan split rasio 1:50. Hasil menunjukkan bahwa penelitian ini mengandung senyawa biodiesel (ester). Senyawa terbanyak ester diperoleh dengan persentase area sebesar $25,227 \%$ pada waktu yang ke 12 menit. Berdasarkan teoritis, kandungan hidrokarbon pada minyak jarak pagar yang terbanyak adalah metil oleat.

\section{Kesimpulan}

1. Yield tertinggi yang diperoleh adalah sebesar $12,80 \%$ pada kondisi 120 menit dan suhu $60{ }^{\circ} \mathrm{C}$ serta perbandingan mol 1:5.

2. Yield yang diperoleh berdasarkan optimasi model Design Expert adalah 12,887 $\%$ pada suhu $60,60{ }^{\circ} \mathrm{C}$ dengan waktu reaksi 131,92 menit serta perbandingan mol $1: 5,03$.

3. Berdasarkan analisa menggunakan Gas Chromatography, biodiesel yang diperoleh memiliki persentasi area sebesar 25,227\% pada waktu ke 12 menit, dengan komponen utamanya adalah metil oleat. 


\section{Daftar Pustaka}

Dogra, S.K. dan S. Dogra. (1990). Kimia Fisik Dan Soal-soal. Universitas Indonesia. Jakarta.

Ma, F., dan Hannah, M.A. (1999). Biodiesel Production: A Review. Bioresource Technology 70, 1-15.

Novalina S., P. (2015). Pembuatan Biodiesel dari Mesokarp Sawit dengan Teknologi Reactive Extraction. Skripsi Program Sarjana Departemen Teknik Kimia USU. Universitas Sumatera Utara. Medan.

Rahmania, O. (2004). Transesterifikasi Minyak Dedak Padi Menjadi Biodiesel dengan Katalis Asam. Surabaya: Thesis Program Pasca Sarjana, Jurusan Teknik Kimia Fakultas Teknologi Industri, Institut Teknologi Sepuluh Nopember. Surabaya.

Supardan, M. D., Satriana, F., Ryan M. (2013). Reactive Extraction of Jatropha Seed for Biodiesel Production Effect of Moisture Content of Jatropha Seed and Co-solvent Concentration. International Journal on Advanced Science Engineering Information Technology 3, 28-31.

Syah, A. N. A. (2006). Biodiesel Jarak Pagar: Bahan Bakar Alternatif yang Ramah Lingkungan. Jakarta. Agro Media Pustaka.

Syam, A.M., Robiah Y., Suraya A, R. (2012). Synthesis of Biodiesel from Refined Bleached Deodorized Palm Oil. LAP Lambert Academic Publishing GmbH \& Co. KG. Jerman. 